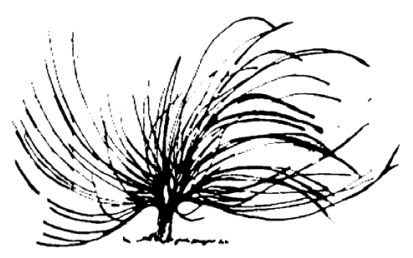

\title{
Tradición cristiana y educación para los derechos humanos: crítica al sentido moral de Nietzsche
}

\author{
Felipe Nicolás Mujica Johnson ${ }^{1}$ \\ Facultad de Ciencias de la Actividad Física y del Deporte \\ Universidad Politécnica de Madrid \\ España \\ fmujica@live.cl
}

Nelly del Carmen Orellana Arduiz ${ }^{2}$

Facultad de Ciencias de la Actividad Física y del Deporte Universidad de Playa Ancha de Ciencias de la Educación

Chile

norellan@upla.cl

\begin{abstract}
Resumen
La filosofía de los derechos humanos contiene la aportación de diferentes tradiciones de pensamiento que han influido en el progreso moral de la humanidad y entre ellas está la tradición cristiana, que contribuyó al concepto de persona y su inherente dignidad universal. No obstante, existen pensadores que niegan el potencial moral de dicha perspectiva, de modo que en este ensayo se abordará el pensamiento de una de ellas. Entonces, el objetivo del presente documento es contrastar las ideas axiológicas del filósofo Friedrich Nietzsche con
\end{abstract}

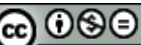

Recibido: 17 de julio de 2019. Aprobado: 28 de octubre de 2019.

http://dx.doi.org/10.15359/rep.15-1.6

1 Magíster en Ciencias de la Actividad Física y del Deporte, Universidad de Playa Ancha de Ciencias de la Educación, Chile. Doctorando en Ciencias de la Actividad Física y del Deporte, Universidad Politécnica de Madrid, España. ORCID: https://orcid.org/0000-0002-6956-2357

2 Máster en Educación Física, Escuela Superior de Deporte, Alemania. Doctora en Filosofía y Educación, Universidad Nacional a distancia, España. Doctora en Filosofía, Leibnis Universität, Alemania. ORCID: https://orcid.org/0000-0002-5742-4539 
la esencia de la moral cristiana y su contribución a la educación de los derechos humanos. Así, se descubre que no es cierto que el sentido moral cristiano se oriente a debilitar o enfermar a las personas, sino que enfoca a su fortalecimiento moral. Precisamente, se hace con la finalidad de que puedan vencer las limitaciones vitales o fisiológicas que dificultan sacrificar el bienestar subjetivo por uno objetivo en el nivel individual y colectivo. De lo contrario, si no se trasciende la naturaleza, no es posible aspirar a fines espirituales como la fraternidad universal. En consecuencia, se reconoce que es fundamental potenciar, en los contextos pedagógicos, una inalienable actitud filosófica frente a los derechos humanos.

Palabras clave: valores morales, educación moral, bienestar social, cristianismo, filosofía de la educación.

\begin{abstract}
The philosophy of human rights contains the contribution of different traditions of thought that have contributed to the moral progress of humanity. And among them is the Christian tradition, which contributed to the concept of person and its inherent universal dignity. However, there are thinkers who deny the moral potential of this perspective, so this essay will address the thinking of one of them. So, the objective of this essay is to contrast the axiological ideas of the philosopher Friedrich Nietzsche with the essence of Christian morality and its contribution to human rights education. Thus, it is discovered that it is not true that the Christian moral sense is aimed at weakening or making people sick, but that it is oriented towards their moral strengthening. Precisely, this is done in order for them to overcome the vital or physiological limitations that make it difficult to sacrifice subjective well-being for an objective wellbeing at the individual and collective levels. Otherwise, if nature is not transcended, it is not possible to aspire to spiritual ends, such as universal fraternity. Consequently, it is recognized that it is fundamental to foster an inalienable philosophical attitude towards human rights in pedagogical contexts.
\end{abstract}


Keywords: moral values, moral education, social welfare, christianity, philosophy of education.

\section{Introducción}

$\mathrm{E}$

n nuestra cultura occidental convergen diferentes perspectivas en torno a la existencia del humano y el sentido de su vida. Una de ellas es la filosófica y teológica cristiana, que contribuyó a la maduración del concepto de persona como categoría cultural, caracterizada por una universal e inalienable dignidad humana (Mari, 2014). Así, en los sucesos históricos más importantes de Occidente, es indiscutible la influencia de los partidarios de dicha doctrina religiosa (también filosófica y pedagógica), quienes han promovido sus ideales. Pero, es igualmente cierto que tales acciones no siempre han sido coherentes con la esencia de la moral que predicaron, de modo que la historia nos enseña dos caras de una misma tradición (Kierkegaard, 1988). Por el lado de la buena cara, nos encontramos las acciones coherentes con el potente mensaje axiológico que desafía y trasciende la naturaleza hacia un plano espiritual, fomentando el progreso de la humanidad a una condición moral cada vez más elevada (Marina, 2005; Messer, 1933; Mujica, 2019a, 2019b; Pascal, 1967; Scheler, 2001, 2005, 2010; Stein, 2003, 2004, 2007; Zubiri, 1955, 1962).

Ese progreso es posible, porque el humano es un animal capaz de frenar sus impulsos o instintos animales en beneficio del bien común de las otras personas (Scheler, 1978). En una idea similar, Zubiri (1985) nos indica que el acontecimiento humano no es "tender estimúlicamente a una nueva situación animal, sino que es tender a situarse realmente de otra manera en la realidad" (p. 45). Precisamente, este ethos cristiano, considerado en este ensayo como el verdadero, pretende florecer dicha condición animal-espiritual. Así, se le otorga un sentido moral a la vida, tendiente hacia fines que trascienden la vida misma, de modo que promueve la dignidad humana como un acto de responsabilidad y compromiso espiritual con las demás personas. Esto se puede ver reflejado en el aporte de la tradición filosófica cristiana a la perspectiva iusnaturalista que precede y cimenta el camino hacia la declaración de los derechos humanos universales (Beuchot, 2004; De La Torre, 2005; Ezcurdia, 1987; Papacchini, 2003). Con respecto al ámbito concreto de la pedagogía, es posible reconocer a destacados educadores quienes, 
inspirados en la doctrina cristiana, han otorgado un notable sentido moral humanista-cristiano a sus obras pedagógicas, resaltando la importancia del amor y la responsabilidad social. Algunos casos son los de James Naismith y José María Cagigal, en el ámbito de la educación física; Johann Pestalozzi, en torno a la educación valórica en contextos formales y no formales, y Paulo Freire, en la formación del profesorado desde una perspectiva crítica orientada a la consecución de mayores cuotas de justicia social (Mujica, 2019a, 2019c; Olivera, 1998).

Por otra parte, la mala cara del cristianismo nos ofrece un actuar totalmente incoherente con la esencia del mensaje de Jesús (Bazán, 2003; Kierkegaard, 1988), el cual se encuentra marcado por hipocresía; violencia física, psicológica y simbólica; la ambición en materia económica y política; el hedonismo irresponsable; en resumen, por la puesta en práctica de acciones fundadas en los disvalores del odio y el egoísmo. Ejemplos bien claros son las guerras santas, la cruel colonización de América y las indignantes redes de pedofilia en el seno de sus iglesias. Esta cara del cristianismo sería denominada, en este ensayo, falso sentido moral cristiano. Por lo mismo, es preciso señalar que la práctica de la verdadera moral cristiana no se reduce a las instituciones religiosas que caminan con el estandarte del cristianismo, sino que se atribuye a cualquier persona quien, independientemente de su estado institucional religioso o espiritual, así como en forma consciente o inconsciente, encarne en su vida el verdadero sentido moral de dicha tradición.

A raíz del surgimiento de aquel falso sentido moral cristiano, sumado a las discrepancias filosóficas con esta doctrina de algunas personas que se aproximan al fundamentalismo, en esta época contemporánea es posible hablar de una tendencia cultural basada en la discriminación hacia dicho conjunto de ideas, nombrada cristianofobia, la cual, al parecer, sería un relevo al antiguo anticlericalismo (Del valle, 2012; Martín, 2009). No obstante, no existe una única interpretación del ideal cristiano (Marina, 2005), lo cual se refleja en las múltiples doctrinas religiosas cristianas, que se diferencian en las interpretaciones realizadas en torno a los evangelios, de modo que el sujeto que encarna dicha oposición al cristianismo se caracterizaría por no aceptar la esencia de la idea cristiana, o sea, la figura de Jesús y su influencia en la sociedad. Precisamente, uno de los filósofos más reconocidos por rechazar la esencia axiológica del cristianismo y negar su contribución a la sociedad es Friedrich Nietzsche (1844-1900). 
Quien nos ilustra sobre este asunto es De la Fuente (2018), señalando que dicho filósofo, por medio de sus escritos, "expresa su desprecio o su asco ante el ser humano moldeado por el cristianismo: condena los instintos fundamentales y valora lo débil y enfermizo. Hay que conseguir otro tipo de hombre, con una conciencia nueva, desvinculada del influjo cristiano" (p. 34). Con base en lo planteado, por medio de este ensayo, se pretende refutar tal debilidad atribuida a los valores morales cristianos, justificando la fortaleza espiritual que requiere la práctica de ese verdadero sentido moral. Por lo tanto, el objetivo de este escrito es contrastar, en forma crítica, las ideas axiológicas del filósofo Friedrich Nietzsche con la esencia de la moral cristiana y su contribución a la educación de los derechos humanos.

\section{Valores morales cristianos y derechos humanos}

Sin duda, Nietzsche (2014) acertó en diferentes críticas al cristianismo, como por ejemplo, el retraso intelectual y científico que propició el pensamiento medieval cristiano en Occidente, el cual fue superado por el racionalismo cartesiano (Ortega y Gasset, 2003). Este retraso es coherente con los principales intereses de dicho pensamiento medieval, avocado, principalmente, a la dimensión moral del humano y descuidando un abordaje integral de la persona. No obstante, es errado pensar que en esa época no se haya contribuido a la evolución de la moral en la sociedad. Otro acierto de Nietzsche (2011) es que logra captar muy bien la amplia propagación existente de la moral cristiana en el mundo occidental, de la cual mucha gente ni siquiera es consciente, no obstante, la prefiere e incluso defiende. Esto sucede porque, evidentemente, la moral humana no se reduce a la vida psíquica e incluye también la vida afectiva (Hartmann, 2011; Scheler, 2001; Stein, 2007). Asimismo, ha logrado capturar la esencia de dicha moral, de modo que en este ensayo se podrá contraargumentar con seguridad el fondo ideológico de la moral nietzscheana.

Antes de abordar algunos de los más importantes valores morales del cristianismo, se presentará la mirada nietzscheana que los demoniza y desprecia. De acuerdo con Nietzsche (2014), el sentido moral cristiano promueve un falso humano superior o elevado espiritualmente, ya que, en realidad, favorecería el desarrollo de personas débiles, bajas o poco elevadas en lo espiritual y fracasadas, debido a que se acostumbrarían a negar su naturaleza instintiva, la que realmente otorga 
una vida vigorosa. En este sentido, para el horizonte moral nietzscheano, la fortaleza cobra un valor muy destacado, pues es la que otorga poder y, entonces, representaría lo bueno o lo que es correcto desear. Justamente, dicho ideal moral es catalogado por Scheler (2001) como un vitalismo promotor de la insensibilidad humana, el cual estaría altamente influenciado por la teoría darwinista, de modo que establece como valores supremos los referidos a los aspectos biológicos y vitales, negando la superioridad de los valores espirituales que están por sobre la conservación de la existencia.

Así, bajo la lógica moral nietzscheana, el humano debiese ser considerado como "animal que ha enfermado" (Scheler, 2001, p. 390), debido a que, gracias a su razón y voluntad, ha dirigido constantemente su vida en oposición a la naturaleza. Por consiguiente, el humano ha de ser un animal que se distingue principalmente por su inteligencia y no por su vitalidad, dado que «dentro de la humanidad, los débiles vitalmente son de modo preferente los poseedores de la "prudencia", del "cálculo", de la "astucia", de la "previsión" y de la racionalización artificiosa de la existencia» (Scheler, 2001, p. 393). Justamente, el pensamiento moral nietzscheano de corte individualista, relativista y vitalista queda bien expresado en las siguientes ideas:

¿Qué es lo bueno? Todo lo que acrecienta en el hombre el sentimiento de poder, la voluntad de poder, el poder mismo. ¿Qué es lo malo? Todo lo que proviene de la debilidad. ¿Qué es la felicidad? La certeza de que se acrecienta el poder; que queda superada una resistencia. Y no ya la satisfacción, sino un incremento del poder; no ya la paz, sino la guerra; no ya la virtud, sino la aptitud (Nietzsche, 2014, p. 22).

Dicho lo anterior, se contrastará, en primera instancia, el valor moral del amor al prójimo o también denominado amor cristiano. El significado de este amor hace referencia a su entrega incondicional a las demás personas que, tomando el modelo de Dios, no exige nada a cambio para que se concrete. Entonces, quien realmente lo vive es capaz de otorgarlo desinteresadamente a personas conocidas o desconocidas y amigas o enemigas, de modo que, además, requiere perdonar y sacrificar diferentes beneficios personales en pos de contribuir a la dignidad ajena. Del mismo modo, el acto de amar implica la disposición 
a aceptar el bienestar y el malestar subjetivo que suscita, por ejemplo, la alegría del bienestar ajeno o el sufrimiento del malestar ajeno (Mujica, Orellana y Pascual, 2019; Rojas, 1993; Scheler, 2005, 2010). Sobre la experiencia virtuosa de este amor, Nietzsche (2011) manifiesta que es un sin sentido, una pérdida de tiempo y una equivocación cultural, ya que quien ama al prójimo lo haría movido realmente por un escaparse de sí mismo, evitando tener que amarse, de modo que sería un abandonarse y un desinterés personal inaceptable.

Lo que indica Nietzsche es medianamente cierto, ya que es indudable que el amor al prójimo requiere postergar el bienestar subjetivo o, en otras palabras, sacrificarse por el prójimo (Mujica, 2019a, 2019b), como bien quedó demostrado en la crucifixión de Jesús, la cual, en una época bastante primitiva en cuanto a los castigos sociales, otorgó una lección moral universal que hasta el día de hoy nos enseña a romper los límites de la tolerancia. Pero esta lección no ha sido la única de similares características, porque, siglos antes, Sócrates se dispuso a sacrificarse por amor a la verdad. Entonces, la falacia del argumento nietzscheano es que el sacrificio del amor es absurdo y debilita el espíritu humano, pues, en ese sentido, es todo lo opuesto, debido a que repercute ampliamente en la fortaleza moral humana, estimulando otros valores, como la solidaridad entre personas, pueblos o naciones. A su vez, transmite una profunda admiración a la valentía y convicción por el bien del prójimo, instando a las demás personas a enfrentar sus limitaciones psicofísicas para progresar moralmente, demostrando la fortaleza espiritual. Por esta razón, Hartmann (2011) sostiene que la corresponsabilidad y la solidaridad que emergen del amor al prójimo podrían ser las fuerzas sociales más profundas y puras que mueven la vida humana. Lo anterior es coherente con la regla de oro que estaría grabada en nuestras conciencias, denominada de esa forma porque destaca en múltiples épocas históricas; esta indica no hacer al otro lo que no te gustaría que te hagan a ti o, al contrario, haz al prójimo lo que te gustaría que te hagan a ti (Ezcurdia, 1987).

Son muchos los acontecimientos socioculturales que reflejan el beneficio social de un comportamiento humano coherente con el amor y contrario al odio, pero ahora me referiré, en particular, a uno vinculado al problema de las muertes en el mar mediterráneo, por el fenómeno de la migración de África a Europa. Precisamente, se hace referencia a la lección moral que otorgó, en junio de 2019, una capitana alemana al 
mando de un barco de rescate de personas migrantes, quien se negó a aceptar que salvar vidas es un acto ilegal y logró rescatar a 42 personas de un muy probable naufragio. Tras pasar 17 días en el mar sin una respuesta favorable del Gobierno italiano, para poner en tierra firme a la tripulación, tomó la valiente decisión de ingresar sin permiso al puerto y cumplir su misión, independientemente de las negativas consecuencias que ello generaría. Entonces, fue detenida por la policía y llevada a la justicia. Por lo tanto, como consecuencia de ayudar a las demás personas, tuvo que soportar una situación bastante sufrida y, por consiguiente, estresante.

No cabe duda de que aquella acción de amor al prójimo no representa a una capitana débil, sino una enorme fortaleza vital y espiritual, lo cual también refleja la dificultad que tiene una gran parte de la población para sacrificar su bienestar individual a favor del ajeno. En términos similares, podemos identificar la fortaleza moral que requiere el amor al prójimo en los actos de protesta que enfrentó con indignación la grave situación fronteriza entre Estados Unidos y México. Tal problemática afectaba a múltiples niños y adultos, quienes llegaron incluso a ser ubicados en jaulas. Aquellas manifestaciones lograron una importante presión para mejorar la situación en forma indirecta, principalmente poniendo el foco de atención mediática en el problema de sus derechos humanos. ¿Qué sería el mundo sin aquellas expresiones de amor al prójimo? ¿Cómo sería el mundo si el ideal moral nietzscheano triunfase ampliamente en la población mundial? Evidentemente, esto no ha sucedido, a pesar de que en la sociedad existe bastante egoísmo y odio, el amor reflejado en la defensa de la dignidad humana y, en consecuencia, en los derechos humanos se encuentra altamente integrado en la moral occidental y cada vez más se hace presente en el mundo oriental. Además, esta amplia adherencia global a los derechos humanos puede ser bien comprendida como un reflejo de la ley objetiva y natural que ordena el progreso de la humanidad (Ezcurdia, 1987; Scheler, 2001).

\section{El peligro sociocultural del superhombre nietzscheano}

El sentido moral relativista y vitalista que promueve Nietzsche $(2011,2014)$ predice la aparición de un humano que ignore y trascienda totalmente los postulados valóricos desarrollados en Occidente, de modo que eliminaría toda categoría sobre lo bueno y lo malo preexistente desde las concepciones espirituales y metafísicas. De esta forma, 
dicho nuevo humano podría resignificar esas mismas categorías en torno a la supremacía de elementos vitales, como el instinto, la fuerza y la voluntad de vivir, en términos generales, sería su voluntad de poder. En palabras de Baigorri, Cifuentes, Ortega, Pichel y Trapiello (1995), el superhombre nietzscheano está dotado de los siguientes ideales:

será la nueva encarnación de aquel dios Dionisos desbordante de vida; el que realmente realice la transvaloración de los valores; será "el sentido de la tierra", lo que da sentido, fin, dirección, a lo terrenal, a ese más acá que nos queda tras la muerte de Dios-; será quien por fin esté más allá del bien y del mal porque será él quien establezca el bien y el mal, como antes lo hiciera aquel Dios muerto (p. 223).

Esta invitación para eliminar todos los criterios valóricos que la humanidad ha establecido a lo largo de sus últimos milenios es muy peligrosa, porque se sustenta en un fundamentalismo que niega los beneficios socioculturales aportados por los múltiples cimientos filosóficos, pedagógicos y teológicos que han estado presentes en nuestra sociedad. Precisamente, para que el sentido moral del superhombre prolifere en los fundamentos filosóficos individuales y colectivos, se requiere alienar a la población en que todos los preceptos anteriores a dichas ideas han sido inútiles. No obstante, el aporte de la tradición cristiana al respeto universal de la dignidad humana y a la posterior declaración de los derechos humanos es inalienable (Beuchot, 2004; De La Torre, 2005; Ezcurdia, 1987; Papacchini, 2003). Cabe destacar que desde la filosofía helénica se realizaron diferentes aportes al concepto de persona, como la singularidad y originalidad humana que destaca Aristóteles (2011), pero es la tradición cristiana la que madura aquella idea antropológica, porque "declara la semejanza entre Dios y el ser humano como originaria e imborrable" (Mari, 2014, p. 307). Por lo tanto, manifiesta el rechazo a todos los argumentos racistas, clasistas y xenófobos, que pretenden negar la dignidad a ciertos grupos humanos.

De acuerdo con Nietzsche (2014), el superhombre debe negar cualquier valor moral que debilite su voluntad de poder, lo acerque al sufrimiento, a la compasión y, por consiguiente, a la bondad humana. Así, para este filósofo, la superioridad humana y su vida digna responden a una concreción de sus deseos sin límites morales, lo cual reflejaría 
su fortaleza, su poder, su voluntad de hacer lo que desea sin que ningún postulado metafísico se lo impida. Y, ¿cómo saber si se está viviendo dignamente? Pues, por medio de factores fisiológicos y corporales que indicarían la potencia animal. De esta forma, evitando convertirse en un animal enfermo que posterga su bienestar subjetivo por el bien de los demás, ante la justificación de la supervivencia, promueve también un sentido hedonista e individualista. Esos ideales no solo han sido combatidos por el cristianismo, cabe recordar que la escuela socrática hizo un gran aporte para elevar al humano a una finalidad que trasciende el bienestar material y lo dirige hacia una meta caracterizada por una vida ascética. Justamente, de ahí se erige la filosofía estoica, con un potente rechazo a la supremacía del placer o el bienestar subjetivo. Y uno de sus principales representantes, Séneca (1984), plantea que quien se entrega al hedonismo es una persona que decide distanciarse de la sabiduría, expresándolo de la siguiente forma:

Pero no llamo sabio a quien tiene algo por encima de sí, y con mayor razón si es el placer. Pues, dominado por éste, ¿cómo hará frente al trabajo y al peligro, a la pobreza y a tantas amenazas que rugen en torno a la vida humana? ¿Cómo soportará la visión de la muerte y el dolor, el estrépito del mundo y tantos enemigos acérrimos, vencido por tan blando adversario? (p. 65)

Entonces, sin duda, adherirse al relativismo y vitalismo valórico es un retroceso moral para la humanidad y la aproximaría al desarrollo de nuevas catástrofes socioculturales, como la del holocausto nazi, en la que un grupo xenófobo y antisemita impuso su voluntad de poder, su placer de ser reconocido como el pueblo con la raza supuestamente más perfecta, el orgullo de conquistar a la población mundial, y todo ello sin ninguna vergüenza y empatía. Es más, de acuerdo con la moral relativista nietzscheana, ¿por qué han de sentir vergüenza?, ¿por qué han de tener arrepentimiento? Por el contrario, amerita celebrar la vitalidad que demostró el régimen nazi por sobre el pueblo judío. Las catástrofes que se pueden asociar a dicho sentido moral son múltiples y la solución siempre será la misma: el progreso de la fraternidad humana. Este anhelo moral todavía encuentra muchas barreras que vencer para concretar un mayor respeto hacia las personas, por ejemplo, el fenómeno de la aporofobia (rechazo a las personas en situación de 
pobreza), que se manifiesta en el nivel universal (Cortina, 2017). Así, es fundamental que se fortalezca una educación intercultural que enfrente dicho fenómeno, como todas las otras fobias socioculturales presentes en la sociedad y que, de esta forma, se contribuya a los actuales desafíos de una ciudadanía intercultural (Cortina, 2006; Mari, 2014). Además, cabe insistir en que se debe potenciar la actitud filosófica frente a tales problemáticas en el ámbito pedagógico escolar y universitario, debido a que "los educadores necesitan una visión amplia, a largo plazo, del sentido de su acción; una visión que conecte sus esfuerzos diarios con la consecución de un futuro mejor para cada uno de sus alumnos y para la sociedad" (Amilburu, 2014, p. 243).

Justamente, no es casualidad que en nuestra época contemporánea los Estados que combaten abiertamente el pensamiento religioso o se acercan a posiciones fundamentalistas de religiones no cristianas son los más denunciados por la vulneración masiva de los derechos humanos. Asimismo, se resisten al desarrollo de una democracia plena, dado que amenazaría la alienación ideológica que sus regímenes autoritarios les permiten. En este sentido, la Unión Europea, a pesar de sus contradicciones, es la región de base social cristiana que más encarna el modelo social de la fraternidad. Por estas razones, es fundamental que los sistemas de educación formal desarrollen una inalienable formación filosófica en torno a los derechos humanos, reconociendo los múltiples acontecimientos y personajes que contribuyeron ideológicamente al repertorio moral universal más admirable de los últimos tiempos. Lo anterior, aunque es claro que hay una importante cantidad de personas que no se suman a dicha admiración y es muy probable que encarnen, en algún aspecto, el sentido moral nietzscheano. No obstante, es preciso trascender esa perspectiva como un acto de responsabilidad para con la sociedad, para, de esta forma, superar "la insensibilidad y las geografías simbólicas del mal” (Mujica et al., 2019, p. 79).

\section{Consideraciones finales}

En función de la crítica realizada al relativismo y vitalismo moral nietzscheano, se advierte que su desarrollo amenaza el complejo progreso que se ha logrado en materia de reconocer la dignidad en términos universales de los humanos. En consecuencia, la concreción de sus derechos como uno de los referentes morales más importantes para establecer la fraternidad al interior de las naciones y entre los mismos pueblos. 
Por lo tanto, se aprecia la necesidad de fortalecer la educación de los derechos humanos que, desde una perspectiva filosófica y antropológica, reconozca el aporte de los ideales morales cristianos. De esta forma, se contribuirá a refutar los argumentos filosóficos que pretenden alienar a las personas con falsos postulados sobre el progreso valórico en la sociedad y que aprovechan los errores o negativos acontecimientos asociados a dichas tradiciones para exagerar la realidad. Precisamente, aquella formación debe incluir los aspectos positivos y negativos de cada doctrina ideológica y teológica, considerando sus aportaciones a la filosofía de los derechos humanos, desvelando, asimismo, los hechos e ideas que contradicen sus planteamientos esenciales.

Se concluye que, esencialmente, la moral cristiana no fomenta la debilidad humana como señalan las ideas vitalistas nietzscheanas, ya que, principalmente, se orienta a fortalecer las cualidades espirituales de las personas, como su voluntad y sus valores, lo cual no es contradictorio con el desarrollo de sus cualidades físicas en contextos adecuados. Precisamente, es cierto que rechaza el fortalecimiento psicofísico, por medio de conductas o situaciones inadecuadas que atenten contra la dignidad humana, pues, por ningún motivo, se enmarca en la idea de que el fin justifica los medios, aunque sucesos históricos hagan parecer lo contrario. Así, que exista una paradoja en torno a los hechos asociados al cristianismo no es un motivo razonable para anular sus ideales, ya que son solo algunos humanos los que hacen posible esas contradicciones, mientras que otros son capaces de encarnar correctamente aquellas ideas. Igualmente, es justo la condición de imperfección humana la que justifica el hecho pedagógico, de modo que, ante las paradojas o contradicciones de los buenos ideales morales, lo correcto es insistir con su proliferación.

\section{Referencias}

Amilburu, M. (2014). Filosofía y actitud filosófica: sus aportaciones a la educación. Revista Española de Pedagogía, 72(258), 231-247. Aristóteles. (2011). Política. Barcelona: Espasa-Calpe.

Baigorri, J.; Cifuentes, L.; Ortega, P.; Pichel, J. y Trapiello, V. (1995). Temas de Filosofia Cou. Madrid: Ediciones del Laberinto.

Bazán, D. (2003). La participación política de los creyentes: esbozo de una fundamentación ético-religiosa. Paulo Freire. Revista de Pedagogía Crítica, 2, 49-59. 
Beuchot, M. (2004). Filosofía y derechos humanos (5. ${ }^{\mathrm{a}}$ ed.). Buenos Aires: Siglo XXI.

Cortina, A. (2006). Ciudadanía Intercultural. Philosophica, 27, 7-15.

Cortina, A. (2017). Aporofobia, el rechazo al pobre. Un desafio para la democracia. Barcelona: Paidós.

De la Fuente, E. B. (2018). Crist(ian)ofobia: más que un fenómeno cultural. Fides et Ratio: revista anual de Teología, Doctrina Social de la Iglesia, Ética y Deontología Profesional, 3, 25-43.

De La Torre, J. (2005). Iusnaturalismo, personalismo y filosofia de la liberación. Una visión integradora. Madrid: MAD.

Del Valle, A. (2012). La nueva cristianofobia, ¿una modalidad del odio a Occidente? Debats, 117, 78-89.

Ezcurdia, J. (1987). Curso de derecho natural. Perspectivas iusnaturalistas de los derechos humanos. Madrid: Reus.

Hartmann, N. (2011). Ética. Madrid: Encuentro.

Kierkegaard, S. (1988). Mi punto de vista. Madrid: Aguilar.

Mari, G. (2014). La aportación del concepto de $<<$ persona $>>$ a la educación intercultural. Revista Española de Pedagogía, 72(258), 299-313.

Marina, J. A. (2005). Por qué soy cristiano. Teoría de la doble verdad. Barcelona: Anagrama.

Martín, A. (2009). Magister vitae. La era de la "cristofobia". La Razón histórica: revista hispanoamericana de historia de las ideas politicas y sociales, 6, 2-4.

Messer, A. (1933). Fundamentos Filosóficos de la Pedagogía (2. a ed.). Barcelona: Labor.

Mujica, F. (2019a). Suscitar buenas emociones en la educación formal: Análisis según la ética de Max Scheler. Revista Dilemas Contemporáneos: Educación, Política y Valores, 6(3), 1-15.

Mujica, F. (2019b). Formación emocional con un sentido moral humanista-cristiano: Análisis en función del amor. Paulo Freire. Revista de Pedagogía Crítica, 21, 126-141.

Mujica, F. (2019c). El sentido moral que James Naismith otorgó al Baloncesto: Una fortaleza para su desarrollo en España y en la Educación Física. EmásF. Revista Digital de Educación Física, 56, 92-103.

Mujica, F.; Orellana, N. y Luis-Pascual, J. C. (2019). Perspectiva moral de las emociones en los contextos de educación 
formal. Ensayos Pedagógicos, 14(1), 69-90. doi: https://doi. org/10.15359/rep.14-1.4

Nietzsche, F. (2011). Así habló Zaratustra. Madrid: Alianza.

Nietzsche, F. (2014). El anticristo. Una maldición sobre el cristianismo. Zarátamo: Maceda.

Olivera, J. (1998). ¿Quién es D. José María Cagigal? Artículo presentado en el Simposio internacional de consenso "José María Cagigal". A Coruña: Universidade Da Coruña. Recuperado de https:// ruc.udc.es/dspace/handle/2183/9752.

Ortega y Gasset, J. (2003). ¿Qué es filosofia? Madrid: Espasa-Calpe.

Papacchini, A. (2003). Filosofia y Derechos Humanos. Cali: Universidad del Valle.

Pascal. (1967). Pensamientos. Madrid: Espasa-Calpe.

Rojas, E. (1993). Una teoría de la felicidad. Madrid: Dossat.

Scheler, M. (1978). El puesto del hombre en el cosmos (13. ${ }^{\mathrm{a}}$ ed.). Buenos Aires: Losada.

Scheler, M. (2001). Ética. Nuevo ensayo de fundamentación de un personalismo ético. Madrid: Caparrós.

Scheler, M. (2005). Esencia y formas de la simpatía. Sígueme: Salamanca.

Scheler, M. (2010). Amor y conocimiento. Y otros escritos. Madrid: Palabra.

Séneca. (1984). Sobre la felicidad (4. ${ }^{a}$ ed.). Madrid: Alianza.

Stein, E. (2003). Escritos esenciales. Santander: Sal Terrae.

Stein, E. (2004). El problema de la empatía. Madrid: Trotta.

Stein, E. (2007). La estructura de la persona humana. Madrid: Biblioteca de Autores Cristianos.

Zubiri, X. (1955). Naturaleza, Historia, Dios. Madrid: Nacional.

Zubiri, X. (1962). Sobre la esencia. Madrid: Sociedad de Estudios y Publicaciones.

Zubiri, X. (1985). El Hombre y Dios. Madrid: Alianza. 